\title{
COST EFFICIENCY IN THE SWISS GAS DISTRIBUTION SECTOR
}

\author{
Mehdi Farsi ${ }^{1,2 *}$ \\ Massimo Filippini ${ }^{1,2}$ \\ Michael Kuenzle ${ }^{1}$ \\ ${ }^{1}$ Department of Management, Technology and Economics \\ ETH Zurich, Zurichbergstr. 18, CH-8032 Zurich, Switzerland \\ ${ }^{2}$ Department of Economics, University of Lugano \\ Via Maderno 24, CH-6900 Lugano, Switzerland
}

January 2006

\begin{abstract}
This paper studies the cost structure of gas distribution utilities in Switzerland. Three stochastic frontier models are applied to a panel of 26 companies operating from 1996 to 2000. Efficiency is assumed to be constant over time. The analysis highlights the importance of output characteristics such as customer density and network size. The results suggest that the utilities could slightly reduce their operating costs by improving efficiency. There is no evidence of significant unexploited scale economies. However, our analysis indicates that the estimates of scale economies could be sensitive to the assumptions regarding the variation of output with output characteristics.

JEL classification: L95; L25

Keywords: cost efficiency; scale economies, gas distribution, stochastic frontier analysis

\footnotetext{
* Corresponding author: Mehdi Farsi, D-MTEC, ETH Zurich, Zurichbergstr. 18, CH-8032, Switzerland. Tel.:

+41-44-632-0656; Fax: +41-44-632-1050; E-mail: mfarsi@ethz.ch

The authors would like to thank the editor and two anonymous referees for their helpful suggestions and Jorg Wild for his support and collaboration.
} 


\section{Introduction}

In the last decade, many countries started to liberalize their energy markets. Since 2000, the European Union has been gradually opening its gas networks to third party access and the consumers are allowed to choose their optimal contracts. Switzerland is expected to follow its neighboring countries and open its gas market to competition. The general idea is to introduce competition in the wholesale and retail markets, and to have a regulated natural monopoly in the transmission and distribution sectors. Therefore, the network access prices need to be regulated. Generally, the regulation can follow a traditional approach such as rateof-return regulation or an incentive-based mechanism like price-cap or yardstick regulation. ${ }^{1}$ The application of these three types of regulation approaches calls for a better understanding of the cost structure and the efficiency of the distribution companies. Especially in the case of incentive-based approaches, the regulator could use this information to induce efficient performance. For instance, predicted costs can be used in setting the yardstick competition targets or the efficiency scores can be used as the X-factor in price cap formulas to reward/punish companies according to their performance. ${ }^{2}$ Moreover, information about the potential scale economies can help the regulators to evaluate the possibilities of cost saving by encouraging mergers and joint ventures among small companies.

Inefficiency in production may come from two different sources: deficiency in applying the technology (technical inefficiency) and suboptimal allocation of resources (allocative inefficiency). Productive inefficiency subsumes these two concepts and can be

\footnotetext{
${ }^{1}$ See Joskow and Schmalensee (1986), Littlechild (1983), Shleifer (1985) and Laffont and Tirole (1993) for a discussion of these approaches.

${ }^{2}$ For a discussion on the use of inefficiency indicators in applied regulation see Rossi and Ruzzier (2000) and Farsi and Filippini (2004).
} 
measured by input or output oriented measures. ${ }^{3}$ One of the commonly used measures of productive inefficiency is the deviation from minimum costs to produce a given level of output with given inputs prices. This measure, although usually referred to as cost inefficiency, does not include the inefficiencies due to suboptimal scale of production.

Generally, there are two main approaches for estimating cost inefficiency: the nonparametric approach originated from operations research, and the econometric approach. ${ }^{4}$ The parametric methods use econometric theory to estimate a cost function with a specified form, where the inefficiency is modeled as additional stochastic term. The non-parametric methods like Data Envelopment Analysis (DEA) calculate an efficient deterministic frontier by linear programming and do not require a pre-specified functional form. Murillo-Zamorano (2004) provides an account of advantages and shortcomings of each one of these methods. In this paper we focus on parametric methods. The main advantage of these methods over nonparametric approaches is the separation of the inefficiency effect from the statistical noise due to data errors and omitted variables.

It should be noted that the results in term of inefficiency obtained using different approaches can be quite different. Thus, it is important to consider certain consistency conditions. Bauer et al. (1998) and Rossi and Ruzzier (2000) propose a series of criteria to evaluate if the inefficiency estimates obtained from different models are "mutually consistent", that is, lead to comparable inefficiency scores and ranks. Farsi and Filippini (2004) recommend using the results of a benchmarking analysis as a complementary instrument in incentive regulation and not in a mechanical way.

\footnotetext{
${ }^{3}$ See Russel (1998) for a discussion of different measures of productive efficiency.

${ }^{4}$ See Kumbhakar and Lovell (2000) for a survey of parametric methods and Coelli et al. (1998), chapter 6, and Simar (1992) for an overview of non-parametric approaches.
} 
The main goal of this paper is to study the sensitivity of inefficiency estimates using panel data models. We apply different parametric models to a five-year panel of 26 Swiss gas distributors. The inefficiency scores estimated from four different models are compared and the consistency of the estimates across different models is discussed. The economies of scale and density are also estimated. A slightly modified definition of scale economies is used to study the sensitivity of the results to the assumption of equi-proportional changes in output characteristics.

The rest of the paper is structured as follows: Section 2 provides a brief review of the empirical literature in gas distribution sector. Section 3 discusses the different cost frontier models used in the paper. The data are described in section 4 . Section 5 presents the estimation results and discusses their implications regarding inefficiencies. Section 6 discusses the results on economies of scale and density. At the end, the main conclusions are summarized.

\section{Review of the literature}

The literature on econometric estimation of cost or production functions in gas distribution companies is scarce. Table 1 lists a selection of these papers. Hollas and Stansell $(1988)^{5}$ are probably the first authors who analyzed this industry by modeling technical and allocative inefficiency. Their model is a behavioral translog profit function that includes output and price "shifters" for four types of companies. Their method allows identifying the relative efficiency of different types with respect to each other, but it does not provide any firm-specific inefficiency estimate. In their specification, they include the price of fuel, labor price, customer density and the fixed capital input measured in daily throughput capacity of the distribution system.

\footnotetext{
${ }^{5}$ See Hollas and Stansell (1994) for a similar application to estimate the economic efficiency of public and private gas distribution utilities.
} 
Kim and Lee (1996) highlight the importance of accounting for output characteristics in estimating a translog cost function for gas distributors. In addition to the labor price and the unit price of pipeline, these authors include the customer density, the average "customer size" measured as average consumption and the "supply rate" measured as the number of total customers relative to the number of total potential customers. Bernard et al. (1998) consider the load factor and the network length as major cost drivers that should be included as output characteristics.

Granderson and Linvill (1999) and Granderson (2000) used an eleven-year panel of 20 U.S. interstate natural gas transmission companies to produce a benchmark for regulation. As inputs, they specify labor, fuel, the weight of the transmission pipelines, and the capacity of compressor station and estimate a translog cost frontier by a random effects GLS model (Schmidt and Sickles, 1984). They also used DEA to get non-parametric estimates of inefficiency and compare the results. Although the results show that when using the nonparametric approach, the inefficiency estimates are lower, the inefficiency ranking stays more or less the same. ${ }^{6}$

Fabbri et al. (2000) estimated a total distribution translog cost function for 31 Italian companies observed during two years. They use the yearly average cost per employee as labor price, the book-value of equipment divided by the length of the distribution network as capital price and the price of material and services is calculated as the residual expenses divided by network length. Output is measured as the volume of gas delivered and the number of customers. Their specification also includes the ratio of network length to the number of customers, share of urban population, the average altitude of the service area, and dummy variables for ownership differences and time effects. Their results suggest a more cost

\footnotetext{
${ }^{6}$ This result is generally consistent with those reported by Carrington et al. (2002) who used the DEA approach and a translog input distance function to estimate efficiency of gas distribution companies.
} 
efficient production in private firms. These authors also found that the economies of scale are not significant at the output levels in the data. On the other hand, economies of density appear to be considerable. These results are in line with most of the findings reported in other studies.

Table 1: An overview of previous studies

\begin{tabular}{|c|c|c|c|}
\hline Author(s) & Database & Functional Form & $\begin{array}{c}\text { Measures of output and } \\
\text { characteristics }\end{array}$ \\
\hline Sing (1987) & $\begin{array}{l}\text { Cross section of } 108 \\
\text { privately owned US gas } \\
\text { and electricity } \\
\text { distribution utilities, } 1981\end{array}$ & $\begin{array}{l}\text { Hybrid translog cost } \\
\text { function with Box-Cox } \\
\text { transformation on } \\
\text { outputs }\end{array}$ & $\begin{array}{l}\text { Volume of gas delivered / } \\
\text { customers per service area }\end{array}$ \\
\hline $\begin{array}{l}\text { Hollas and Stansell } \\
\text { (1988) }\end{array}$ & $\begin{array}{l}\text { Cross section of } 64 \\
\text { privately owned US } \\
\text { natural gas distribution } \\
\text { utilities, } 1981\end{array}$ & $\begin{array}{l}\text { Translog profit function } \\
\text { with quantity and price } \\
\text { shifters }\end{array}$ & Volume of gas delivered \\
\hline Kim and Lee (1996) & $\begin{array}{l}\text { Panel of } 7 \text { Korean gas } \\
\text { distributors, } \\
\text { 1987-1992 }\end{array}$ & $\begin{array}{l}\text { Translog cost function / } \\
\text { OLS }\end{array}$ & $\begin{array}{l}\text { Volume of gas delivered / } \\
\text { customer density, average } \\
\text { customer size, supply rate }\end{array}$ \\
\hline Bernard et al. (1998) & $\begin{array}{l}\text { Cross section of } 131 \\
\text { Canadian gas extension } \\
\text { projects }\end{array}$ & Box-Cox cost function & $\begin{array}{l}\text { Max. daily demand / pipe } \\
\text { length }\end{array}$ \\
\hline $\begin{array}{l}\text { Granderson and } \\
\text { Linvill (1999) } \\
\text { and } \\
\text { Granderson (2000) }\end{array}$ & $\begin{array}{l}\text { Panel of } 20 \text { US natural } \\
\text { gas transmission } \\
\text { companies, } \\
\text { 1977-1987 }\end{array}$ & $\begin{array}{l}\text { Translog cost function / } \\
\text { random effects model }\end{array}$ & Volume of gas delivered \\
\hline Fabbri et al. (2000) & $\begin{array}{l}\text { Panel of } 31 \text { Italian } \\
\text { distribution companies, } \\
\text { 1991-1992 }\end{array}$ & $\begin{array}{l}\text { Translog cost function / } \\
\text { SURE }\end{array}$ & $\begin{array}{l}\text { Volume of gas delivered / } \\
\text { Inverse of customer } \\
\text { density, average altitude, } \\
\text { population density }\end{array}$ \\
\hline Rossi (2001) & $\begin{array}{l}\text { Panel of } 8 \text { Argentinean } \\
\text { gas distribution } \\
\text { companies, } \\
1993-1997\end{array}$ & $\begin{array}{l}\text { Cobb-Douglas } \\
\text { production function / } \\
\text { COLS and Battese and } \\
\text { Coelli (1992) model }\end{array}$ & $\begin{array}{l}\text { Volume of gas delivered / } \\
\text { service area, share of } \\
\text { residential to total sales, } \\
\text { maximum demand }\end{array}$ \\
\hline
\end{tabular}

Rossi (2001) estimated a stochastic frontier production function using the approach suggested by Battese and Coelli (1992). Rossi used the network length as a proxy for capital input, and the number of employees as the labor input. In addition, the concession area, the ratio of residential sales to total sales and the maximum demand are considered as the environmental variables. The number of customers is used as a single output. In one of his specifications the results suggest significant diseconomies of scale, but another model's results do not reject the hypothesis of optimal scale. 


\section{Methodology}

A frontier cost function defines minimum costs given output level, input prices and the existing production technology. Failure to attain the cost frontier implies the existence of technical and/or allocative inefficiency. This section provides a description of the cost frontier models and the specification used in this paper. The adopted methodology is based on a comparison of different models with respect to the estimated cost function parameters and estimated inefficiency scores. The main goal is to study the limitations of different models in benchmarking and the sensitivity of inefficiency scores to econometric modeling.

\subsection{Cost Frontier Models}

In this paper, we consider the estimation of a stochastic frontier cost function using different panel data models. The theoretical development of stochastic frontier models in panel data has been subject of a great body of literature. ${ }^{7}$ Recent developments such as random parameter frontier models usually require relatively large samples with sufficient variation. Considering the small size of our sample and the limited number of periods these methods do not appear to be effective. ${ }^{8}$ Considering the characteristics of our data set and the purpose of the paper, we decided to use three classical frontier models for panel data and a variant of one of these models.

The first model is the stochastic cost frontier approach proposed by Aigner et al. (1977). This model is a cross sectional model but could be applied to a panel data set by

\footnotetext{
${ }^{7}$ See Kumbhakar and Lovell (2000) for a review and Greene (2005) and Tsionas (2002) for some recent developments.

${ }^{8}$ In a preliminary analysis we applied some of these models especially the true random effects proposed by Greene $(2005,2004)$. The results generally indicate that due to the insufficient variation in the data, some of the random terms degenerate to zero. This suggests that these types of specifications are too rich for our data. For an application of these models in other network industries, see Farsi et al. (2006, 2005a).
} 
pooling the data across different years. This model, which we refer to as the "pooled model", can be written as:

$$
\ln C_{i t}=\ln C\left(y_{i t}, w_{i t}\right)+u_{i t}+v_{i t} \quad u_{i t} \geq 0, i=1,2, \ldots ., N \text { and } t=1,2, \ldots, T .(1)
$$

In this specification the error term is composed of two independent parts: The first part $u_{i t}$, is a one-sided non-negative disturbance reflecting the effect of inefficiency, and the second component vit, is a symmetric disturbance capturing the effect of noise. The statistical noise is assumed to be normally distributed, while the inefficiency term $u_{i}$ is assumed to follow a half-normal distribution. This model can be estimated using Maximum Likelihood Estimation (MLE) method. Individual inefficiencies can be estimated by the conditional expectation of the inefficiency term, $E\left(u_{i t} \mid u_{i t}+v_{i t}\right)$, proposed by Jondrow et al. (1982).

In the pooled model, a given firm's inefficiency is supposed to vary with time, but could take a value completely independent of its level in the previous years. An extension of this model applied to panel data has been proposed by Pitt and Lee (1981). This model can be written as follows:

$$
\ln C_{i t}=\ln C\left(y_{i t}, w_{i t}\right)+u_{i}+v_{i t} \quad u_{i} \geq 0, i=1,2, \ldots ., N \text { and } t=1,2, \ldots, T .(2)
$$

In this specification it is assumed that the inefficiency term $u_{i}$, follows a half-normal distribution across firms but stays constant over time within a given firm. Although this assumption might appear unrealistic given the fairly long period covered in the sample, our preliminary analyses indicate that the temporal variations of inefficiency are not significant in our data. ${ }^{9}$ Similarly, this model is estimated using MLE and the individual inefficiencies

\footnotetext{
${ }^{9}$ We first explored the time variation by including a linear trend and year dummies in explanatory variables. None of these time variables showed any significant effect. We also applied an extension of Pitt and Lee (1981)'s model proposed by Battese and Coelli (1992) in which the inefficiency is assumed to follow a time-
} 
are estimated by the conditional expectation of the inefficiency term, ${ }^{10}$ given by $E\left(u_{i} \mid \varepsilon_{i 1}, \ldots, \varepsilon_{i T}\right)$, where $\varepsilon_{i t}=u_{i}+v_{i t}$ with $t=1,2, \ldots, T$.

The assumptions about the distribution of the random terms $u_{i}$ and $v_{i t}$ can be relaxed by rewriting equation 2 as:

$$
\ln C_{i t}=\ln C\left(y_{i t}, w_{i t}\right)+\alpha+u_{i}^{*}+v_{i t} \text { with } u_{i}=u_{i}^{*}-\min \left\{u_{i}^{*}\right\} \text { and } \alpha=\min \left\{u_{i}^{*}\right\},
$$

where $u_{i}^{*}$ is the firm-specific random effect. The resulting model, proposed by Schmidt and Sickles (1984), can be estimated using the feasible Generalized Least Squares method.

The remaining restrictive assumption is that the random effects are uncorrelated with the observed characteristics included in the cost function. Schmidt and Sickles (1984) propose a solution to relax this assumption by using the fixed effects specification. The main shortcoming of this model is that the inefficiency measures may be confounded with timeinvariant factors, which could not be included in the model. ${ }^{11}$ To avoid this problem and at the same time controlling for the potential correlation of firm-specific effects with explanatory variables, we applied Mundlak (1978)'s formulation to the GLS model. ${ }^{12}$ The correlation of firm-specific unobserved effects with explanatory variables are captured in an auxiliary equation given by:

$$
\alpha_{i}=\gamma \overline{\mathbf{X}}_{\mathbf{i}}+\delta_{i}, \text { where } \overline{\mathbf{X}}_{\mathbf{i}}=\frac{1}{T_{i}} \sum_{t=1}^{T_{i}} \mathbf{X}_{\mathbf{i t}} \text { and } \delta_{i} \sim \operatorname{iid}\left(0, \sigma_{\delta}^{2}\right)
$$

varying exponential decay function. The results indicate that the coefficient of time is statistically insignificant. Moreover, the estimated efficiencies are very close to those obtained from the Pitt and Lee model.

${ }^{10}$ Jondrow et al. (1982) provide the expression for conditional mean in cross sectional data. The extension for panel data is given in Kumbhakar and Lovell (2000), page 111 and Greene (2002), section 24.

${ }^{11}$ See Farsi and Filippini (2004) for a discussion of advantages and drawbacks of fixed and random effects models.

${ }^{12}$ See also Farsi et al. (2005b) for a similar specification. 
$\mathbf{X}_{\mathbf{i t}}$ is the vector of all explanatory variables and $\boldsymbol{\gamma}$ is the corresponding vector of coefficients. This formulation divides the firm-specific term into two components: The first part can be explained by the exogenous variables and is interpreted as heterogeneity, whereas the remaining component $\delta_{\mathrm{i}}$ is orthogonal to the explanatory variables and is assumed to reflect the company's inefficiency. Equation (4) is incorporated in the main regression equation:

$$
\ln C_{i t}=\ln C\left(y_{i t}, w_{i t}\right)+\gamma \overline{\mathbf{X}}_{\mathbf{i}}+\delta_{i}+v_{i t} \quad \text { with } \quad u_{i}=\delta_{i}-\min \left\{\delta_{i}\right\}
$$

This model is estimated by the GLS method. Mundlak (1978) showed that this formulation of the GLS model results in a coefficient vector of $\ln C\left(y_{i t}, w_{i t}\right)$ that is equivalent to the within estimator (fixed effects model) and thus would be unbiased even in presence of firm effects that are correlated with explanatory variables. ${ }^{13}$ It should be noted that the fixed effects model (FE) can also be used to estimate the inefficiencies (as proposed by Schmidt and Sickles, 1984). However, we do not use the FE model here, because the estimated coefficients in this model do not bring any additional value to our study as they are exactly equal to those obtained from the GLS model with Mundlak's adjustment. Moreover, the inefficiency estimates from the FE model are overestimated because they include some of the factors (such as area size and customer density) that are almost time-invariant. This issue has been highlighted in an example reported by Farsi and Filippini (2004).

\subsection{Specification of the Cost Function}

Gas distribution companies operate in networks with different shapes and environmental characteristics, which directly affect costs. The output is measured as total volume of natural gas delivered. Input factors consist mainly of the gas purchased from a transmission company, labor and capital. Therefore, there are in principle two alternatives for

\footnotetext{
${ }^{13}$ For a proof of this statement, see also Hsiao (2003), Section 3.4.2a.
} 
measuring inefficiency: an integrated total cost approach and a network operating cost approach, where expenditures for gas purchases are excluded. The network costs approach has a practical advantage in that the estimated average costs can be directly used in a pricecap formula. However, this approach neglects the potential inefficiencies in the choice of the gas delivery contract. Therefore, in this paper we adopt the total cost approach. The cost function is specified as:

$$
T C=f\left(Y, P_{C}, P_{L}, P_{E}, L F, T B, C U D, A S I Z E\right),
$$

where $T C$ represent total costs; $Y$ is the energy value of the delivered gas measured in $\mathrm{MWh}$; and $P_{C}, P_{L}$ and $P_{E}$ are respectively the prices of capital, labor and purchase price of natural gas. In addition to these variables, we also include the load factor $L F$, the number of terminal blocks $T B$, the customer density CUD and the area size ASIZE as output characteristics.

The load factor is defined as the ratio of annual average flow of gas to the annual peak flow per hour. It is a measure of how constant the network capacity is used throughout the year. A higher value of load factor implies a lower variation in consumption. The load factor is a demand characteristic and cannot be directly influenced by the company. A network with a low load factor needs more capacity. We therefore expect the coefficient of the load factor to be negative, implying lower costs for companies with more evenly distributed network use.

The number of terminal blocks $(T B)$ is another output characteristic included in the model. Terminal blocks are usually located at the entrance of the buildings and serve several end-users. It is also possible that two or more buildings share a terminal block when they are internally connected. Typically, a terminal block is owned and maintained by the gas distribution company, whereas the pipeline following the block belongs to the customer. The number of blocks is expected to have a positive effect on costs through higher hookup, maintenance and billing costs. Often, the customer density, measured as number of clients per 
kilometer of network length (CUD), is also considered as an important indicator of costs. ${ }^{14}$ The average maintenance cost per customer is lower in networks with higher density, suggesting a negative sign for CUD. The area size (ASIZE) of each utility is included to measure the company's size. ${ }^{15}$ Larger service areas generally require larger and more spread networks, thus more operating and maintenance costs.

The regularity conditions require that the cost function in equation (6) be nondecreasing in input prices and output, and linearly homogeneous and concave in input prices. ${ }^{16}$ In the empirical literature, two main functional forms have been used: the translog and the Cobb-Douglas form. In general, the translog form provides a more flexible framework especially regarding the scale economies, which can vary with the output. However in this paper, given the small size of the sample and the large number of parameters ${ }^{17}$ in the translog model, we use the Cobb-Douglas form.

The Cobb-Douglas specification of the cost function in (6) can be written as:

$$
\begin{aligned}
\ln \left(\frac{T C}{P_{L}}\right) & =\alpha_{0}+\alpha_{Y} \ln Y+\alpha_{C} \ln \left(\frac{P_{C}}{P_{L}}\right)+\alpha_{E} \ln \left(\frac{P_{E}}{P_{L}}\right)+\alpha_{L F} L F \\
& +\alpha_{T B} \ln T B+\alpha_{C U D} \ln C U D+\alpha_{A S I Z E} \ln A S I Z E
\end{aligned}
$$

\footnotetext{
${ }^{14}$ Sing (1987) uses customers per square mile of service area as density.

${ }^{15}$ An alternative measure would be the network length. Given that the latter variable is highly correlated with the area size (correlation coefficient of 0.94 ), we decided to use the actual length of the network in calculating the capital price and customer density and the area size as a measure of the utility's size.

${ }^{16}$ See Cornes (1992) for a discussion of the properties of cost functions.

${ }^{17}$ In our specification the number of coefficients in translog model would be 36 , which results in a relatively small number of degrees of freedom in a sample of 26 companies with 129 observations.
} 
The linear homogeneity condition is imposed by normalizing costs and prices to the labor price. All variables except the load factor are in logarithms. The load factor is a positive value lower than one, thus is not transformed into logarithm. ${ }^{18}$

\section{Data}

Based on the year 2000 statistics, there are about 128 gas distribution companies in Switzerland. Generally, the distribution companies own the distribution network in which they operate and there is no overlap between the service areas of individual companies. The transmission network is owned and operated by Swiss Gas, a company mainly held by four major public regional gas distributors. Swiss Gas is in charge of transmitting about three fourths of the total national gas consumption. The remaining part is delivered by the transmission pipelines owned by neighboring countries. Distributors purchase the gas from transmission companies and deliver it through their own distribution networks to the end-use consumers.

The data used in this paper is based on a mail survey from 26 distribution companies accounting for about 57 percent of the total gas consumption in Switzerland. These companies participated in the survey in a voluntary basis. None of the four regional companies are included. All the participants except one provided the data for five years from 1996 to 2000 . The 1996 data is not available for one company. Thus, the sample consists of 129 observations. The data collected consist of financial and technical information.

The companies in the sample represent about a fifth of Swiss gas distributors but own about 40 percent of the total length of the gas distribution network in Switzerland. This implies that many small gas distributors are under-represented in the sample. Moreover, the

\footnotetext{
${ }^{18}$ We also estimated the model with logarithm of LF. The estimated inefficiencies (not reported here) do not vary much and show a very high correlation with those estimated from the adopted models (generally higher than 0.99).
} 
average volume of distributed gas per network length in these companies is higher than the national average value. With regard to the service area, our sample covers $42 \%$ of all Swiss communities served with gas. Table 2 provides a descriptive summary of the main variables used in the analysis. Total costs $T C$ are the total annual operating costs plus the gas purchases from the transmission sector. Tax expenditures and non-operating costs are excluded. Output $Y$ is measured by the total amount of gas delivered to end-consumers and to downstream distributors. $^{19}$

Table 2: Descriptive statistics (129 observations)

\begin{tabular}{|c|c|c|c|c|}
\hline Variables & Mean & $\begin{array}{l}\text { Standard } \\
\text { Deviation }\end{array}$ & Minimum & Maximum \\
\hline $\begin{array}{l}\text { Total annual costs }(T C) \\
\text { Thousand CHF }\end{array}$ & 21411 & 24477 & 2592 & 135382 \\
\hline $\begin{array}{l}\text { Annual output }(Y) \\
\text { in MWh }\end{array}$ & 548515 & 729301 & 58000 & 4174000 \\
\hline $\begin{array}{l}\text { Average annual labor price }\left(P_{L}\right) \\
\text { CHF per employee }\end{array}$ & 96161 & 15963 & 61830 & 139460 \\
\hline $\begin{array}{l}\text { Average annual capital price }\left(P_{C}\right) \\
\text { CHF per meter network length }\end{array}$ & 28.56 & 11.43 & 12.53 & 75.78 \\
\hline $\begin{array}{l}\text { Average annual energy price }\left(P_{E}\right) \\
10^{-2} \mathrm{x} \text { CHF per } \mathrm{kWh}\end{array}$ & 2.51 & 0.47 & 1.65 & 3.82 \\
\hline Load Factor $(L F) \%$ & 34.99 & 6.68 & 14.51 & 57.91 \\
\hline Number of customers (NUMB) & 4537 & 5744 & 509 & 29605 \\
\hline Number of terminal blocks $(T B)$ & 4423 & 5691 & 756 & 29575 \\
\hline Service area (ASIZE) in hectares & 2104 & 1840 & 320 & 8310 \\
\hline $\begin{array}{l}\text { Number of customers } \\
\text { per km network length (CUD) }\end{array}$ & 20.26 & 7.19 & 4.34 & 32.57 \\
\hline Network length in km & 214.3 & 213.4 & 37.7 & 1122 \\
\hline
\end{tabular}

- All monetary values are in 2000 Swiss Francs (CHF), adjusted by the consumer price index.

Labor price $\left(P_{L}\right)$ is defined as the ratio of total annual labor costs, including social security costs, to the number of full time equivalent employees. The price of energy $\left(P_{E}\right)$ is

\footnotetext{
${ }^{19}$ About one fourth of the companies have gas resale to other distributors. In an alternative specification (not reported here) we controlled for these companies with a dummy variable. Since this dummy is not significantly different from zero we decided to exclude it from the final specification.
} 
the average unit price of the purchased gas. The capital price $\left(P_{C}\right)$ is calculated as sum of expenditures other than labor expenses and gas purchases divided by the network length. These expenditures include interest payments and depreciation as well as material costs and other services included in operating costs. Capital stock includes the distribution network as well as other equipment such as monitoring and control systems and the final connections and metering equipment. In fact, lacking any other reliable measure of total capital stock, we assumed that the capital stock is more or less proportional to the network length. Moreover, as the network is the major part of the capital stock of a gas distributor, network length has been used as a proxy physical measure of capital in the calculation of capital prices. All costs and prices are adjusted for inflation using the Switzerland's consumer price index and are measured in year 2000 Swiss Francs.

\section{Estimation Results}

Estimation results for the four models are given in table 3. Results show that the output and input price coefficients are positive and highly significant across all models. Furthermore, the coefficients are not significantly different from one model to another, suggesting the results for the parameters do not depend on distributional assumptions of the error and inefficiency term. All output characteristics show the expected signs, although the coefficient of the load factor is only significantly different from zero in the GLS model. ${ }^{20}$

The results indicate that all the group mean coefficients in the GLS-Mundlak model are insignificant at $5 \%$. This finding is supported by the Hausman test, which does not reject the hypothesis of similar coefficients between the GLS and fixed-effects models (P-value of 0.39). This in turn suggests that the firm effects are not correlated with the explanatory variables. Compared to other models, the model with Mundlak adjustment show generally higher standard errors. In particular, the coefficient of the service area is not significantly different from zero (at 5\% significance level). This result can be explained by the fewer

\footnotetext{
${ }^{20}$ Similar results were obtained using the logarithm of the load factor.
} 
degrees of freedom in this model. Another important observation is that the estimated coefficients from the pooled model are more or less similar to those obtained from the three panel data models. This result also suggests that the firm-specific unobserved factors do not create a significant bias in the coefficients.

Table 3: Regression results

\begin{tabular}{|c|c|c|c|c|}
\hline Coefficient & Pooled & Pitt \& Lee & GLS & $\begin{array}{c}\text { GLS \& } \\
\text { Mundlak }\end{array}$ \\
\hline$\alpha_{Y}$ & $\begin{array}{l}0.718^{*} \\
(0.012)\end{array}$ & $\begin{array}{l}0.691^{*} \\
(0.034)\end{array}$ & $\begin{array}{l}0.696^{*} \\
(0.021)\end{array}$ & $\begin{array}{c}0.638^{*} \\
(0.058)\end{array}$ \\
\hline$\alpha_{\mathrm{PC}}$ & $\begin{array}{l}0.259^{*} \\
(0.013)\end{array}$ & $\begin{array}{l}0.262^{*} \\
(0.021)\end{array}$ & $\begin{array}{l}0.248^{*} \\
(0.016)\end{array}$ & $\begin{array}{l}0.250^{*} \\
(0.021)\end{array}$ \\
\hline$\alpha_{\mathrm{PE}}$ & $\begin{array}{l}0.624^{*} \\
(0.021)\end{array}$ & $\begin{array}{l}0.589^{*} \\
(0.030)\end{array}$ & $\begin{array}{l}0.596^{*} \\
(0.020)\end{array}$ & $\begin{array}{l}0.588^{*} \\
(0.022)\end{array}$ \\
\hline$\alpha_{\mathrm{LF}}$ & $\begin{array}{l}-0.175 \\
(0.075)\end{array}$ & $\begin{array}{l}-0.243 \\
(0.193)\end{array}$ & $\begin{array}{c}-0.283^{*} \\
(0.098)\end{array}$ & $\begin{array}{l}-0.158 \\
(0.146)\end{array}$ \\
\hline$\alpha_{\mathrm{TB}}$ & $\begin{array}{l}0.198^{*} \\
(0.014)\end{array}$ & $\begin{array}{l}0.225^{*} \\
(0.047)\end{array}$ & $\begin{array}{l}0.202 * \\
(0.030)\end{array}$ & $\begin{array}{l}0.259^{*} \\
(0.090)\end{array}$ \\
\hline$\alpha_{\text {ASIZE }}$ & $\begin{array}{l}0.089^{*} \\
(0.015)\end{array}$ & $\begin{array}{l}0.091^{*} \\
(0.032)\end{array}$ & $\begin{array}{l}0.117^{*} \\
(0.033)\end{array}$ & $\begin{array}{c}0.164 \\
(0.100)\end{array}$ \\
\hline$\alpha_{\text {CUD }}$ & $\begin{array}{c}-0.155^{*} \\
(0.015)\end{array}$ & $\begin{array}{c}-0.194 * \\
(0.075)\end{array}$ & $\begin{array}{c}-0.163^{*} \\
(0.026)\end{array}$ & $\begin{array}{l}-0.278^{*} \\
(0.074)\end{array}$ \\
\hline$\alpha_{0}$ & $\begin{array}{l}2.798^{*} \\
(0.202)\end{array}$ & $\begin{array}{l}2.712^{*} \\
(0.477)\end{array}$ & $\begin{array}{l}2.565^{*} \\
(0.276) \\
\end{array}$ & $\begin{array}{l}2.926^{*} \\
(0.593)\end{array}$ \\
\hline$\gamma_{Y}$ & & - & - & $\begin{array}{c}0.082 \\
(0.064)\end{array}$ \\
\hline$\gamma_{\mathrm{PC}}$ & & - & - & $\begin{array}{c}0.012 \\
(0.038)\end{array}$ \\
\hline$\gamma_{\mathrm{PE}}$ & & - & - & $\begin{array}{c}0.048 \\
(0.069)\end{array}$ \\
\hline$\gamma_{L F}$ & & - & - & $\begin{array}{l}0.0656 \\
(0.251)\end{array}$ \\
\hline$\gamma_{\mathrm{TB}}$ & & - & - & $\begin{array}{l}-0.064 \\
(0.097)\end{array}$ \\
\hline$\gamma_{\text {ASIZE }}$ & & - & - & $\begin{array}{l}-0.073 \\
(0.108)\end{array}$ \\
\hline \multirow[t]{3}{*}{$\gamma_{\text {CUD }}$} & & - & - & $\begin{array}{c}0.137 \\
(0.080) \\
\end{array}$ \\
\hline & $\sigma_{\mathrm{v}}=0.030$ & $\sigma_{\mathrm{v}}=0.027$ & $\mathrm{~S}_{\mathrm{v}}=0.028$ & $\mathrm{~s}_{\mathrm{v}}=0.028$ \\
\hline & $\sigma_{\mathrm{u}}=0.072$ & $\sigma_{\mathrm{u}}=0.077$ & $\mathrm{~s}_{\mathrm{u}}=0.054$ & $\mathrm{~s}_{\mathrm{u}}=0.052$ \\
\hline
\end{tabular}

- $\quad$ Standard errors are given in brackets. * means significantly different from zero at least at $99 \%$.

- $\quad \mathrm{s}_{\mathrm{v}}$ and $\mathrm{s}_{\mathrm{u}}$ in the GLS models are respectively the standard deviation of residuals associated with $\mathrm{v}_{\mathrm{it}}$ and $\mathrm{u}_{\mathrm{i}}$. In Pitt and Lee's model, $\sigma_{\mathrm{v}}$ and $\sigma_{\mathrm{u}}$ are the model parameters and are statistically significant at $\mathrm{p}=0.05$.

Since total costs and the relevant explanatory variables are in logarithms, the estimated coefficients can be interpreted as cost elasticities. For instance, the output coefficient suggests 
that on average, a one percent increase in the amount of gas delivered will increase the costs by about 0.7 percent. Similarly, a one percent increase in the number of terminal blocks will increase the costs by about 0.2 percent. The cost elasticities with respect to factor prices are positive and of similar magnitude in all models. The estimated coefficient for capital price $\left(\alpha_{\mathrm{PC}}\right)$ represents the share of costs attributed to capital, which is about 25 percent. This result is very close to the average capital share in the actual data of about 29 percent. Also, the value of the coefficient of energy price $\left(\alpha_{\mathrm{PE}}\right)$ reflects its share in the sample of about 59 percent.

As expected, the negative sign of the coefficient of the load factor suggests that networks that are more evenly utilized throughout the year, are relatively less costly. The results also indicate that the customer density has a negative effect on total costs (negative $\left.\alpha_{\text {CUD }}\right)$. The coefficient of area size $\left(\alpha_{\text {ASIZE }}\right)$ is consistent with the contention that ceteris paribus larger areas imply longer distances, thus higher organization and maintenance costs. Moreover, larger networks are more likely to be complex.

Table 4 provides a descriptive summary of the inefficiency estimates. These estimates denoted by $u_{i}$ in our models, represent the relative excess cost of a given firm compared to a minimum level that would have been achieved if the firm had operated as efficiently as the "best practice" observed in the sample. The results suggest an average inefficiency of 6 to 7.5 percent (median values of 5 to 7 percent), which is quite stable across models. As it can be seen in the table the inefficiency estimates obtained from the pooled model and Pitt and Lee specification are quite similar. The fact that the assumption regarding the temporal variation of inefficiency does not affect the results, suggests that the inefficiencies could be considered as more or less constant over time. Constant efficiency estimates are not surprising, because although one might expect to observe changes in efficiency over the five-year sample period, the studied companies operate in a heavily regulated system that has not changed significantly. The results also show that the extreme inefficiency estimates slightly decrease 
when the correlation of unobserved firm-specific variables is taken into account (Mundlak formulation).

Table 4: Inefficiency measures

\begin{tabular}{l|cccc}
\hline & Pooled & Pitt \& Lee & GLS & $\begin{array}{c}\text { GLS \& } \\
\text { Mundlak }\end{array}$ \\
\hline Mean & 0.058 & 0.058 & 0.075 & 0.075 \\
Median & 0.045 & 0.048 & 0.068 & 0.071 \\
Maximum & 0.191 & 0.194 & 0.193 & 0.180 \\
95th Percentile & 0.144 & 0.183 & 0.182 & 0.156 \\
Minimum & 0.012 & 0.009 & 0.000 & 0.000 \\
\hline
\end{tabular}

The pairwise Pearson correlation matrix of the inefficiency estimates presented in table 5, shows a generally high correlation. This suggests that the estimates are reasonably robust to specification. The results of Spearman rank correlation (omitted from the paper) are similar to those in table 5. However, our analysis of efficiency ranks indicates that although the most and least efficient firms remain stable across different models, the companies in the first and last quintiles change from one model to another. These results indicate that Bauer et al. (1998)'s mutual consistency criteria are not fully satisfied. Therefore, the estimated individual inefficiency scores could incur considerable estimation errors that could also affect ranks. The results are consistent with Horrace and Schmidt (1996) who show that even a panel with 6 periods cannot provide reasonable estimates of individual efficiency scores. The results are however more reliable concerning the average inefficiency in the sector or in a group of companies. As shown in table 4, on average inefficiency is responsible for about 5 to 7 percent of the operating costs in the Swiss gas distribution utilities. 


\section{Table 5: Pairwise Pearson correlation between inefficiency estimates}

\begin{tabular}{c|c|cc}
\hline & Pooled & Pitt \& Lee & GLS \\
\hline Pitt \& Lee & 0.837 & 1 & \\
GLS & 0.850 & 0.956 & 1 \\
$\begin{array}{c}\text { GLS \& } \\
\text { Mundlak }\end{array}$ & 0.857 & 0.873 & 0.935 \\
\hline
\end{tabular}

\section{Economies of scale and density}

In the cost function framework, returns to scale can be defined in terms of the relative changes in costs due to an increase in output, namely the inverse of output elasticity in a cost function. ${ }^{21}$ In network industries however, the output variation is generally together with a change in output characteristics such as network size. In such cases, the concept of density economies is used to describe the effect of changes in output with the network characteristics being fixed (cf. Caves, Christensen and Tretheway, 1984 and Caves et al., 1985). As for the scale economies it is generally assumed that, in line with Caves, Christensen and Swanson (1981), as the production scale increases, all outputs and output characteristics vary at the same proportion. In this case the economies of scale can be defined as the inverse of the sum of the elasticities with respect to outputs and output characteristics, whereas the economies of density are defined as the inverse of output elasticity. ${ }^{22}$ Based on these definitions, when scale or density economies are greater than one, the production operates at increasing returns to

\footnotetext{
${ }^{21}$ In general, this definition differs from the concept of returns to scale in production, which is defined as the change in output resulting from an equi-proportional increase in inputs. Chambers (1988) makes the distinction by referring to the cost-based measure as "returns to size". However, in the case of homothetic production functions (as assumed in this paper), these measures coincide.

${ }^{22}$ See also Farsi et al. (2006) for the mathematical expression and Panzar and Willig (1977) for a formal definition.
} 
scale, suggesting potential savings by increasing output. Conversely, values lower than one indicates diseconomies of scale.

Table 6 lists the values of scale and density economies based on the above definitions estimated from the GLS-Mundlak specification. Since the coefficients of the estimated models do not differ much across specifications, in this section we focus on the GLSMundlak model. The confidence intervals have also been listed in the table. As scale and density economies are non-linear functions of the estimated coefficients, we used the delta method $^{23}$ to calculate the standard errors and the confidence intervals. These results show that the value of economies of density is larger than one, suggesting that distributors could lower their average costs by increasing the output if the service area and the number of customers remain constant. This is reflected by the value of the output coefficient $\alpha_{Y}$, which implies that a one percent increase in output would increase costs by about 0.64 percent.

Table 6: Economies of scale and density

\begin{tabular}{l|c|c|cc}
\hline \multicolumn{1}{c|}{ Measure } & Term & Value & \multicolumn{2}{c}{$\begin{array}{c}\text { Confidence } \\
\text { Interval }\end{array}$} \\
\hline Economies of density & $1 / \alpha^{Y}$ & 1.57 & 1.28 & 1.86 \\
Economies of scale & $1 /\left(_{\alpha Y}+{ }_{\alpha{ }^{\top B}}+{ }_{\alpha \text { ASIZE }}\right)$ & 0.94 & 0.80 & 1.09 \\
\hline
\end{tabular}

- 95\% confidence intervals are calculated by the delta-method.

If in the process of increasing output, both area size and number of customers increase with the same proportion, the economies of scale falls to 0.94 , which is not significantly different from one (see table 6). This result, more or less consistent with the previous literature $^{24}$, suggests that on average extending the network does not help to save operating costs. However, these results are based on the conventional definition of multiproduct

\footnotetext{
${ }^{23}$ The delta method is an intuitive method to estimate the standard errors of any function of random variables, such as coefficient estimates in a regression model. See Oehlert (1992) for more details.

${ }^{24}$ For a summary on economies of scale in gas distribution networks, see Fabbri et al. (2000).
} 
economies of scale, which assumes that all outputs and output characteristics increase by the same proportion. This assumption could be unrealistic in practice. For instance a ten percent extension of the network might result in a lower increase in output, because the newly connected customers could have a lower density and consumption. Especially, this relationship might also depend on the network and environmental characteristics of the company. In fact a simple analysis of changes over the sample period shows that despite relatively strong inter-correlation, the output characteristics do not vary at the same proportions.

The data indicate that while the company's gas output has shown an average growth of about 9 percent over the sample period, the number of terminal blocks have grown by 11 percent on average and the covered area size by about 4 percent. ${ }^{25}$ Moreover, the ratio of change differs across companies. Focusing on the ten companies with a non-zero change in their network over the sample period, we calculated the ratio of relative change in an output characteristic to the relative change in the amount of delivered gas (output $Y$ ) for each company. This ratio is on average about $1.7,1.3$ and 0.3 respectively for the number of terminal blocks (TB), area size (AS) and customer density (CUD). These values suggest that for the companies that had any extension over the sample period, one percent increase in output has been on average, associated with $1.7 \%$ extension in area size, $1.3 \%$ increase in the number of terminal blocks and a small increase of $0.3 \%$ in customer density. This implies that a given increase in output may require a larger extension in the network.

The assumption of equal proportions can be relaxed by weighting the elasticities of each output by its corresponding variation ratio with respect to output. Table 7 gives two variants of scale economies considering non-uniform proportions. The variation ratios $\left(\rho_{\mathrm{TB}}\right.$, $\rho_{\text {ASIZE }}$ and $\left.\rho_{\text {CUD }}\right)$ can be specified according to the case at hand. Here, we set these values to their

\footnotetext{
${ }^{25}$ In 16 out of 26 companies the area size has remained constant.
} 
corresponding estimates from the data. The first variant measures the economies of scale associated with an increase in output, when the number of terminal blocks and the area size and therefore the network are extended but the customer density remains constant, while the second variant includes the additional effect of customer density. Economies of scale 1 (table 7) can be compared with its equi-proportional counterpart in table 6 . The results suggest that the scale economies may be overestimated if all changes are considered with the same proportion. As table 7 shows, in both variants, the economies of scale are lower than one, suggesting diseconomies of scale. However, given that the estimates are sensitive to the adopted values for the proportions, these results cannot be generalized and should be considered with caution.

Table 7: Economies of scale redefined

\begin{tabular}{c|c|c|cc}
\hline Measure & Terms & Value & $\begin{array}{c}\text { Confidence } \\
\text { Interval }\end{array}$ \\
\hline Economies of scale 1 & $1 /\left(\alpha \mathrm{Y}+\rho^{\mathrm{TB}} \alpha^{\mathrm{TB}}+\rho^{\mathrm{AS}} \alpha \mathrm{ASIZE}\right)$ & 0.78 & 0.64 & 0.93 \\
Economies of scale 2 & $1 /\left(\alpha_{\mathrm{Y}}+\rho^{\mathrm{TB}} \alpha^{\mathrm{TB}}+\rho^{\mathrm{AS}} \alpha \mathrm{ASIZE}+\rho_{\mathrm{CUD}} \alpha \mathrm{CUD}\right)$ & 0.83 & 0.66 & 0.99 \\
\hline
\end{tabular}

- $\rho_{\text {TB }}, \rho_{\text {ASIZE }}$ and $\rho_{\text {CUD }}$ are respectively the ratios of relative change in TB, ASIZE and CUD to the relative change in output $(Y)$ over the sample period. These values averaged over the ten companies with non-zero change are $\rho_{\mathrm{TB}}=1.66, \rho_{\mathrm{ASIZE}}=1.30$ and $\rho_{\mathrm{CUD}}=0.26$. Confidence intervals are at $95 \%$ confidence level and are calculated by the delta-method. The estimation errors of the slopes are neglected in calculating the confidence interval.

\section{Conclusions}

The application of three cost frontier models to a five-year panel of 26 gas distribution companies in Switzerland suggests an average inefficiency of about seven percent in the sector. This result is robust across all the models. The individual efficiency scores and ranks estimated from different models show a strong correlation. However, the companies identified as "best" and "worst" practices change across models. These results show that the mutual "consistency" requirements (Bauer et al., 1998) are not fully satisfied. Therefore, the individual efficiency estimates cannot be directly used as X-factors in price cap formulas. 
However, the robustness of average efficiency estimates and also the cost function coefficients across different specifications suggest that the results can be used in setting target efficiency scores and cost prediction. The regulators can use such instruments to improve efficiency through yardstick competition.

The results also highlight the importance of environmental and output characteristics. Especially, the customer density, measured as number of customers per kilometer of network, has a decreasing effect on costs, while the area size has a positive effect. As for the scale and density economies the results are more or less consistent with the findings of studies performed in other countries, in that they provide evidence of considerable density economies but insignificant or weak scale economies. This implies that distributors could decrease their average costs by increasing the output as long as they use the same network but the extension of networks does not result in any significant economies. Our analysis of variations over the sample period shows that the output characteristics do not vary at the same proportion as assumed in the definition of the scale economies. An alternative definition that accounts for the proportions estimated from the sample, suggests that the estimates of scale economies might be sensitive to the assumptions on the proportions between outputs.

\section{References}

Aigner, D., C. A. K. Lovell and P. Schmidt (1977). "Formulation and Estimation of Stochastic Frontier Production Function Models", Journal of Econometrics, 6, 21-37.

Battese, George E. and Tim J. Coelli (1992). "Frontier production functions, technical efficiency and panel data: with application to paddy farmers in India”, Journal of Productivity Analysis, 3 (1): 153-169. 
Bauer, Paul W., Allen N. Berger, Gary D. Ferrier, and David B. Humphrey (1998). "Consistency conditions for regulatory analysis of financial institutions: A comparison of frontier efficiency methods", Journal of Economics and Business, 50: 85-114.

Bernard, J.-T., D. Bolduc, and A. Hardy (1998), The Marginal Cost of Natural Gas Distribution Pipelines: The Case of Société en Commandite Gaz Métropolitain, Québec, Working Paper, Département d'économique, Université Laval Québec, Canada.

Battese, G. E. and T. J. Coelli (1992), Frontier Production Functions, Technical Efficiency and Panel Data: with Application to Paddy Farmers in India, Journal of Productivity Analysis 3, 153-169.

Carrington, R., T. Coelli, and E. Groom (2002), International Benchmarking for Monopoly Price Regulation: The Case of Australian Gas Distribution, Journal of Regulatory Economics 21 (2), 191-216.

Caves, D. W., L. R. Christensen, and J. A. Swanson (1981): "Productivity Growth, Scale Economies, and Capacity Utilization in U.S. Railroads, 1955-74", The American Economic Review, 71 (5): 994-1002.

Caves, D. W., L. R. Christensen, and M. W. Tretheway (1984): "Economies of Density versus Economies of Scale: Why Trunk and Local Service Airline Costs Differ". Rand Journal of Economics, 15 (4): 471-489.

Caves, Douglas W., L. R. Christensen, M. W. Tretheway, and R. J. Windle (1985) 'Network effects and the measurement of returns to scale and density for U.S. railroads', in Analytical Studies in Transpot Economics, editor. A. F. Daugherty, Cambridge University Press, pp. 97-120.

Chambers, R. G. (1988), Applied Production Analysis, Cambridge University Press. 
Coelli, T. J., D. S. P. Rao, and G. E. Battese (1998), An Introduction to Efficiency and Productivity Analysis, Boston, Kluwer Academic Publishers.

Cornes, R. (1992). Duality and Modern Economics, Cambridge University Press.

Cornwell, C., P. Schmidt, and R. C. Sickles (1990), Production Frontiers with Cross-Sectional and Time-Series Variation in Efficiency Levels, Journal of Econometrics 46 1-2, 185-200.

Fabbri, P., G. Fraquelli, and R. Giandrone (2000), Costs, Technology and Ownership of Gas Distribution in Italy, Managerial and Decision Economics 21, 71-81.

Farsi, M. and Filippini M., (2004), Regulation and Measuring Cost Efficiency with Panel Data Models Application to Electricity Distribution Utilities, The Review of Industrial Organization, 25 (1): 1-19.

Farsi, Mehdi, Massimo Filippini and Michael Kuenzle (2006). 'Cost efficiency in regional bus companies: An application of new stochastic frontier models', Journal of Transport Economics and Policy, 40 (1): 95-118.

Farsi, Mehdi, Massimo Filippini and William Greene (2005a). 'Efficiency Measurement in Network Industries: Application to the Swiss Railway Companies', Journal of Regulatory Economics, 28 (1): 65-86.

Farsi, Mehdi, Massimo Filippini and Michael Kuenzle (2005b). "Unobserved Heterogeneity in Stochastic Cost Frontier Models: An Application to Swiss Nursing Homes", Applied Economics, 37, 2127-2141.

Friedlaender, A. and S. J. W. Chang (1983), Productivity Growth in the Regulated Trucking Industry, Research in Transport and Economics 1, 149-184.

Granderson, G. (2000), Regulation, Open-Access Transportation, and Productive Efficiency, Review of Industrial Organization 16, 251-266. 
Granderson, G. and C. Linvill (1999), Parametric and Nonparametric Approaches to Benchmarking the Regulated Firm, Journal of Productivity Analysis 12 (3), 211-231.

Greene, William (2002). LIMDEP version 8.0, Econometric Modeling Guide, Volume 2, Econometric Software, Inc., Plainview, NY, USA.

Greene, William (2005). "Reconsidering Heterogeneity in Panel Data Estimators of the Stochastic Frontier Model”, Journal of Econometrics, 126 (2): 269-303.

Greene, William (2004). "Distinguishing between heterogeneity and inefficiency: Stochastic frontier analysis of the World Health Organization's panel data on national health care systems", Health Economics 13: 959-980.

Hollas, D. and St. R. Stansell (1988), Regulation, Interfirm Rivalry, and the Economic Efficiency of Natural Gas Distribution Facilities, The Quarterly Review of Economics and Business 28 (4), 21-37.

Hollas, D. and St. R. Stansell (1994), The Economic Efficiency of Public vs. Private Gas Distribution Utilities, Annals of Public and Cooperative Economics 65(2), 281-300.

Horrace, W. C., and P. Schmidt (1996). "Confidence statements for efficiency estimates from stochastic frontier models” Journal of Productivity Analysis, 7:257-282.

Hsiao, Cheng (2003). Analysis of Panel Data, $2^{\text {nd }}$ edition, Cambridge University Press.

Jondrow, J., C. A. K. Lovell, I. S. Materov, and P. Schmidt (1982), On the Estimation of Technical Inefficiency in the Stochastic Frontier Production Function Model, Journal of Econometrics 19 (2-3), 233-238.

Joskow, P. J., and R. Schmalensee (1986), Incentive Regulation for Electric Utilities, Yale Journal of Regulation 4 (1), 1-49. 
Kim, T.-Y. and J.-D. Lee (1996), Cost Analysis of Gas Distribution Industry with Spatial Variables, The Journal of Energy and Development 20 (2), 247-267.

Kumbhakar, Subal C., and C. A. Knox Lovell (2000), Stochastic Frontier Analysis, Cambridge: Cambridge University Press.

Laffont, J.-J. and J. Tirole (1993), A Theory of Incentives in Procurement and Regulation, MIT Press, Cambridge, USA.

Mundlak, Yair (1978). "On the pooling of time series and cross section data" Econometrica, 64 (1): 69-85.

Murillo-Zamorano, Luis R. (2004), Economic Efficiency and Frontier Techniques, Journal of Economic Surveys, 18 (1): 33-77.

Oehlert, G. W. (1992), 'A note on the delta method', American Statistician, 46 (1): 27-29.

Panzar, J. C. and R. D. Willig (1977), Economies of Scale in Multi-Output Production, Quarterly Journal of Economics, 91 (3), 481-493.

Roberts M. J. (1986), Economies of Density and Size in the Production and Delivery of Electric Power, Land Economics, 62 (4), 378-387.

Rossi, M. A. and Ch. A. Ruzzier (2000), On the Regulatory Application of Efficiency Measures, Utilities Policy 9 (2), 81-92.

Rossi, M. (2001), Technical Change and Efficiency Measures: the Post-Privatisation in the Gas Distribution Sector in Argentina, Energy Economics 23, 295-304.

Russel, R. R. (1998): "Distance Functions in Consmer and Producer Theory”, in Index Number Theory: Essays in Honor of Sten Malmquist, Editors: R. Färe, R. Poos and R. R. Russel, Boson: Kluwer Academic Publishers. 
Schmidt, P. and R. C. Sickles (1984), Production Frontiers and Panel Data, Journal of Business and Economic Statistics 2 (4), 367-374.

Simar, Leopold (1992), Estimating Efficiencies from Frontier Models with Panel Data: A Comparison of Parametric, Non-parametric and Semi-parametric Methods with Bootstrapping, Journal of Productivity Analysis 3, 171-203.

Sing, M. (1987), Are Combination Gas and Electric Utilities Multiproduct Natural Monopolies?, Review of Economics and Statistics 69 (3), 392-398.

Tsionas, E. G. (2002), Stochastic Frontier Models With Random Coefficients, Journal of Applied Econometrics 17, 127-147. 